\title{
Determination of Lamotrigine, Carbamazepine and Carbamazepine Epoxide in Human Serum by Gas Chromatography Mass Spectrometry ${ }^{1}$ )
}

\author{
Jürgen Hallbach, Hermann Vogel and Walter G. Guder \\ Institute for Clinical Chemistry, Bogenhausen Hospital, Munich, Germany
}

\begin{abstract}
Summary: A method for the identification and quantification of the antiepileptics lamotrigine, carbamazepine and carbamazepine epoxide (active metabolite) in human serum is described. In refractory epilepsy the combination of carbamazepine and lamotrigine was recently developed to a modern therapeutic concept. The goal of this paper is therapeutic drug monitoring (TDM) of these substances. Serum was extracted with a quick precipitation method using a modified commercial extraction-kit and analysed by gas chromatography mass spectrometry (GC-MS). A gas-chromatographic temperature-pressure programme was developed that allowed the determination of lamotrigine by gas chromatography mass spectrometry. A reference spectrum of pure lamotrigine is herewith published for the first time. A new mass spectra library was created to support the identification of the antiepileptics in human serum. In the Specified Ions Monitoring mode (SIM) a detection limit below the therapeutic range and recoveries above $90 \%$ were obtained.
\end{abstract}

Comparison of results obtained by GC-MS or a commercially available high performance liquid chromatographic (HPLC) method (for lamotrigine) and a fluorescence polarisation immunoassay (FPIA) (for carbamazepine) from spiked serum samples showed disagreement of no more than $10 \%$ between the methods and demonstrated the accuracy of the new method. In addition, quantitative determinations of these antiepileptics in samples from patients under anticonvulsive therapy showed a strong linear correlation with $\mathrm{r}^{2}=0.961$ for carbamazepine and $\mathrm{r}^{2}=0.964$ for lamotrigine. Only two from a total of 46 results differed by more than $10 \%$.

Our method for quantifying lamotrigine in serum seems to be highly specific and capable of measuring lamotrigine in patients on single therapy, as well as on add-on therapy with carbamazepine or carbamazepine epoxide. No interference from other coadministered drugs was detected.

\section{Introduction}

Lamotrigine is a new antiepileptic drug and has recently shown promise in add-on therapy with other antiepileptic drugs in refractory epilepsy and for resistant partial seizures (1).

Therapeutic drug monitoring of antiepileptics can help to optimize therapeutic efficiency and patient safety. The relationship between the concentration of lamotrigine and other antiepileptic drugs in plasma and their therapeutic effect has been described in many studies $(1-3)$. Serum concentrations in responding patients receiving chronic treatment with lamotrigine and exhibiting therapeutic effects were seen to be $0.9-1.8 \mathrm{mg} / \mathrm{l}$ (4), in practice a therapeutic range from $0.5-4.5 \mathrm{mg} / 1$ was found (5). As with other antiepileptics, therapy with lamotrigine should be controlled by therapeutic drug monitoring. In the early nineties HPLC and immunoassay determinations of lamotrigine in serum were described (6-8). However, only HPLC assays have been commercially available up to now.

\footnotetext{
1) Preliminary results were presented as poster at the IFCC congress in London 1996 (Proc XVI ICCC 1996, 114).
}

In this paper we describe the development of a new GCMS method, combined with a modified commercially available HPLC extraction kit, which gave us the possibility to determine lamotrigine together with carbamazepine and carbamazepine epoxide in blood during add-on therapy in one analytical run.

\section{Materials and Methods}

Reagents

Carbamazepine was obtained from Abbott Diagnostics (Wiesbaden, Germany), Imipramine (intemal standard) from Sigma $\mathrm{GmbH}$ (Deisenhofen, Germany), lamotrigine was purchased from Wellcome (Wedel, Germany) and drug-free serum from Bio-Rad Laboratories (Munich, Germany). Carbamazepine epoxide was a gift from Recipe (Munich, Germany) and extraction vials containing a buffered salt mixture were purchased from Recipe (No. 15020).

Methanol, acetonitrile and ethylacetate were purchased from Promochem GmbH (Wesel, Germany).

All standard solutions $(1000 \mathrm{mg} / \mathrm{l}$ solved in methanol) were stored at $-70^{\circ} \mathrm{C}$ until use, for shorter times (some weeks) storage at $-20^{\circ} \mathrm{C}$ seems sufficient.

Instrumentation

A Hewlett Packard 5972 Mass Spectrometer combined with a Hewlett Packard 5890 series II plus gas chromatograph was used. 
Tab. 1 Ion group start time, retention time and selected ions of antiepileptic drugs in the single ion monitoring mode.

\begin{tabular}{|c|c|c|c|c|c|c|c|}
\hline \multirow[t]{2}{*}{ Compound } & \multirow{2}{*}{$\begin{array}{l}\text { Group-start time } \\
\text { [min] }\end{array}$} & \multirow{2}{*}{$\begin{array}{l}\text { Retention time } \\
\text { [min] }\end{array}$} & \multicolumn{5}{|c|}{ Ions in group } \\
\hline & & & $(\mathrm{m} / \mathrm{e})$ & & & & \\
\hline Carbamazepine-epoxide & 11.00 & 11.38 & 179 & 178 & 151 & & \\
\hline Imipramine (IS) & 12.00 & 12.09 & 234 & 193 & 130 & 85 & 58 \\
\hline Carbamazepine & 12.50 & 12.72 & 193 & 165 & 236 & 96 & 146 \\
\hline Lamotrigine & 13.15 & 13.63 & 185 & 187 & 123 & 255 & \\
\hline
\end{tabular}

Tab. 2 Detection limits in Scan- and single ion monitoring (SIM) mode and masses for quantification.

\begin{tabular}{llll}
\hline Compound & $\begin{array}{l}\text { Detection limit } \\
\text { SIM-mode } \\
{[\mathrm{mg} / 1]}\end{array}$ & $\begin{array}{l}\text { Detection limit } \\
\text { SCAN-mode } \\
{[\mathrm{mg} / \mathrm{l}]}\end{array}$ & $\begin{array}{l}\text { Mass for } \\
\text { quantification }\end{array}$ \\
\hline Carbamazepine epoxide & 0.5 & 15 & 179 \\
Carbamazepine & 0.5 & 5 & 193 \\
Lamotrigine & 0.25 & 10 & $185 ; 187 ; 255$ \\
\hline
\end{tabular}

It was equipped with a split-splitless injector and a capillary column DB-5ht (length $30 \mathrm{~m}, \mathrm{I}$. D. $0.250 \mathrm{~mm}$, film $0.100 \mu \mathrm{m}$ ) from J\&W Scientific (ICT, Bad Homburg, Germany).

The gas chromatographic conditions were: injection temperature $250^{\circ} \mathrm{C}$; transferline heater temperature $325^{\circ} \mathrm{C}$; helium flow-rate $0.815 \mathrm{ml} / \mathrm{min}$; injection volume: $2 \mu \mathrm{l}$ splitless. The temperature programme started at $60^{\circ} \mathrm{C}$, this was held for 2 minutes, within 1 min the temperature was increased to $120^{\circ} \mathrm{C}$ and held another 2 min, then the temperature was increased by $20^{\circ} \mathrm{C}$ per min and held finally for $1 \mathrm{~min}$ at $25^{\circ} \mathrm{C}$.

The MS conditions in SCAN-mode were: Tuning masses 264, 219 , $131 \mathrm{~m} / \mathrm{e}$ added with 200 EMV (Electron Multiplier Voltage); mass range $40-550 \mathrm{~m} / \mathrm{e}$, solvent delay $10 \mathrm{~min}$; threshold $=200$.

In the SIM-mode the same conditions were used, except that 400 EMV were added. The selected masses for identification and quantification and the ion-group-start time were as shown in table 1 .

Carbamazepine was also measured by FPIA using the TDx /FLx analyzer from Abbott (Wiesbaden, Germany). Lamotrigine was additionally measured by reversed phase HPLC. Thereby the same extraction procedure and a commercially available isocratic HPLC method with UV-detection from Recipe (Kit No. 15100) were used.

\section{Samples, tubes, storage}

Blood was taken in $4.5 \mathrm{ml}$ Vacutainer ${ }^{(B)}$ serum separator tubes (Becton Dickinson, Heidelberg, Germany). Serum was stored at $4{ }^{\circ} \mathrm{C}$, for periods up to 7 days at $-70^{\circ} \mathrm{C}$.

\section{Procedures}

\section{Extraction of antiepileptics}

In principle a combination of precipitation and liquid extraction was used. Serum $(0.1 \mathrm{ml})$ and $0.15 \mathrm{ml}$ precipitation reagent (acetonitril containing imipramine $5 \mathrm{mg} / \mathrm{l}$ as internal standard) were added to the prepared extraction vials. After vortexing for $30 \mathrm{~s}$ and centrifugation ( $5 \mathrm{~min}$ at $10000 \mathrm{~g}$ ) $0.1 \mathrm{ml}$ of the organic supernatant was evaporated to dryness with $\mathrm{N}_{2}$ at room temperature and the residue dissolved in $50 \mu$ l ethylacetate.

\section{Identification of antiepileptic drugs}

As peak integrator the Chem-Station-Integrator from Hewlett Packard was used. Critical conditions were adjusted to: initial area reject activated, initial peak width 0.020 , shoulder detection off, initial threshold 8 .

The conditions for library-search-strategy were: prefilter-control (U-A) adjusted to 3, tilting to off, crosscorrelation to off, minimum estimated purity $50 \%$. A library of mass-spectra, prepared by us, was used for the identification of antiepileptics. It contained adapted spectra from PMW TOX2 Mass Spectral Database (9) or NIST/EPA/NIH Mass Spectral Database (Hewlett Packard Company, Palo Alto, CA) as well as spectra of pure substances examined by us in the SCAN and SIM modes. The mass spectrum of lamotrigine was recorded for the first time in our laboratory and verified with a sector field mass spectrometer at the pharmaceutical faculty of Ludwig Maximilians University (Munich, Germany).

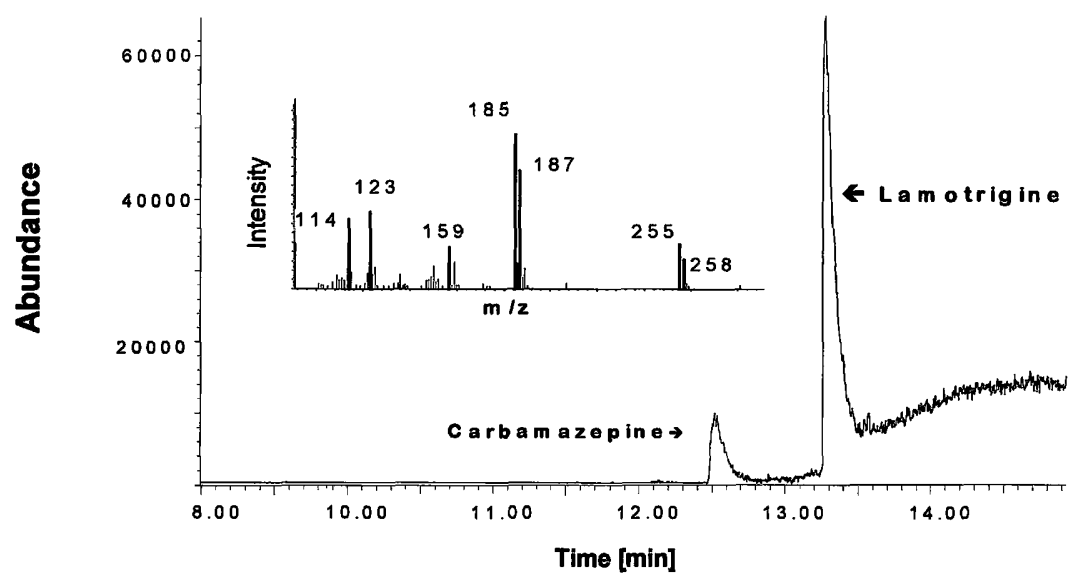

Fig. 1 Chromatogram of pure carbamazepine $(3 \mathrm{mg} / \mathrm{l})$ and lamotrigine $(50 \mathrm{mg} / \mathrm{l})$ in the SCAN-mode. The mass spectrum of lamo- trigine was taken from the library database created with our own standards. 


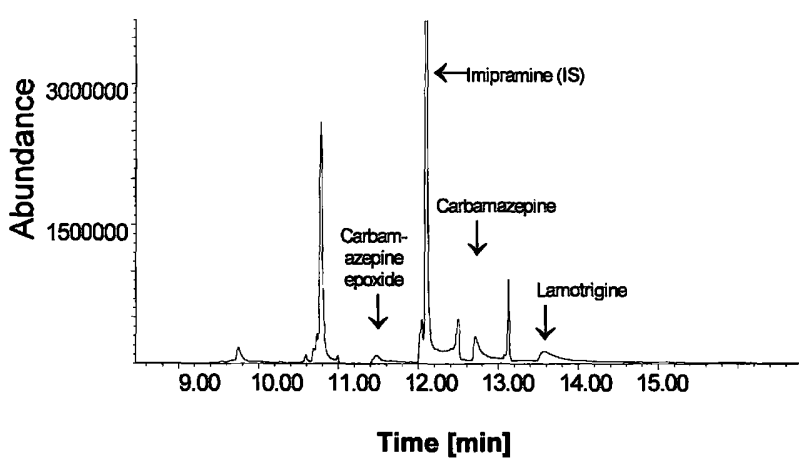

Fig. 2 Chromatogram in SIM-mode of a patient sample, containing carbamazepine, carbamazepine epoxide, lamotrigine and imipramine (internal standard, IS). The antiepileptic drugs were extracted as described in the methods section. The selected masses and retention times are documented in table 1.

For probabilities greater than $65 \%$ we searched the Pfleger-Maurer (9) library. If this was not successful, we changed automatically to the library we created. This enabled us in the scan-mode to recognize other drugs in addition. No gas-chromatographic interferences with the antiepileptics were detected. In the SIM-mode we only used our own library.

\section{Quantification of antiepileptic drugs}

We used the dominant mass of each antiepileptic drug and the selected internal standard for quantification (tab. 2). The calibration for carbamazepine epoxide, carbamazepine and lamotrigine was obtained from six drug free serum samples containing $0 ; 0.625$; $1.25 ; 2.5 ; 5.0 ; 10.0 ; 20.0 \mathrm{mg} / 1$ of these drugs. Imipramine was used as internal standard.

\section{Results and Discussion}

\section{Identification and quantification of antiepileptic drugs}

Lamotrigine and carbamazepine were extracted from spiked serum (concentration of lamotrigine was $50 \mathrm{mg} / \mathrm{l}$, of carbamazepine $6 \mathrm{mg} / \mathrm{l}$ ) and separated by GC-MS. In the total ion chromatogram individual peaks were obtained (fig. 1). The extraction procedure of the manufac- turer for HPLC analysis was changed by drying and redissolving the eluate in pure ethylacetate. This resulted in a clean extract and gave high recoveries of the antiepileptic drugs. The insert in figure 1 shows the mass spectrum of lamotrigine. The dominant fragment mass(es) of each substance were selected for quantification (SIM-mode). Due to the low chromatographic response of lamotrogine the signals of three masses (tab. 2) were used after summation. Figure 2 shows a chromatogram of lamotrigine, carbamazepine epoxide and carbamazepine in the SIM-mode together with the internal standard imipramine. With this procedure the detection limits (tab. 2) were found to be beyond the therapeutic levels $(4,5)$.

Typical calibration curves are given in figure 3. For all compounds an excellent correlation was found between standard amount and signal (tab. 3). In addition, this table shows the intraassay precision data of our quantification method. CV's were found between 3 and $12 \%$. Accuracy could not be tested with quality control materials (lacking target values for GC-MS), but was determined with spiked serum samples. Analysis of 10 to 30 (for lamotrigine) spiked serum samples showed analytical recoveries between 90 and $111 \%$ for all drugs.

\section{Assay correlation}

The results obtained with GC-MS and immunoassay (for carbamazepine) or HPLC (for lamotrigine) were compared using the Passing-Bablok method. The correlation coefficients $\left(\mathrm{r}^{2}\right)$ were higher than 0.95 and the regression lines obtained for carbamazepine and lamotrigine are shown in figure $4 a$ and $b$. Only two results for lamotrigine disagreed by more than $10 \%$. The results obtained by GC-MS were repeatedly higher. The nature of the differences could not be explained, particularly, no such differences were seen with stock samples.

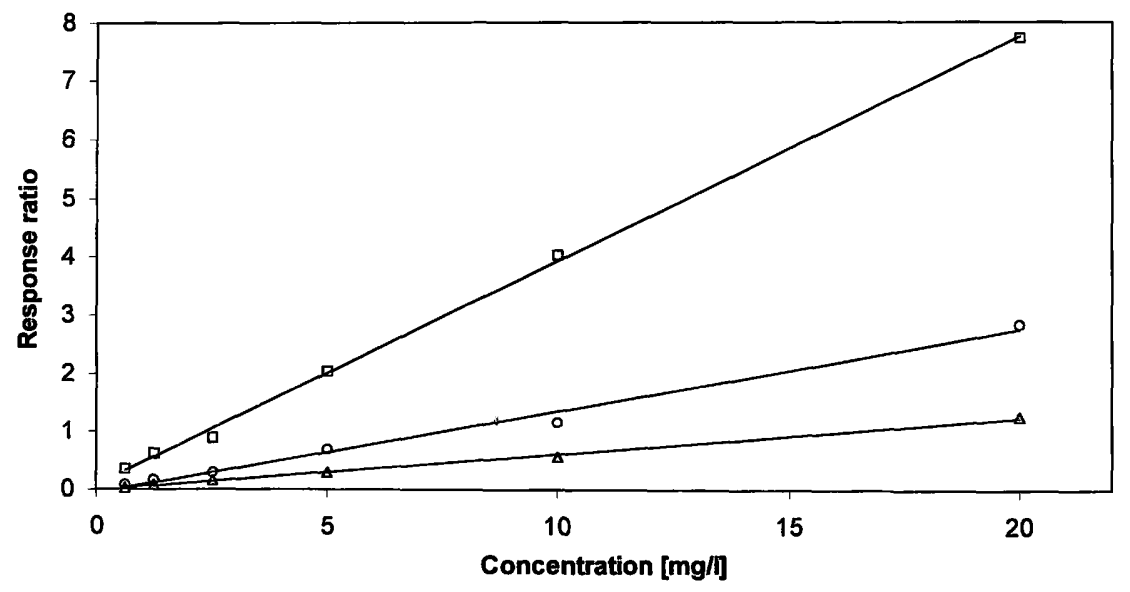

Fig. 3 Calibration curves of carbamazepine (squares), carbamazepine epoxide (circles) and lamotrigine (triangles). The concentrations of the standards (extracted from $0.1 \mathrm{ml}$ serum) were $0 ; 0.625$;
$1.25 ; 2.5 ; 5.0 ; 10.0 ; 20.0 \mathrm{mg} / \mathrm{l}$. Imipramine was used as internal standard (IS). The masses selected for quantification are given in table 2; linearity is documented in table 3. 
Tab. 3 Non-parametric regression correlation parameters (linearity), recovery and precision data for carbamazepine epoxide, carbamazepine and lamotrigine.

\begin{tabular}{|c|c|c|c|c|c|c|}
\hline Compound & $r^{2}$ & $\begin{array}{l}\text { Amount added } \\
{[\mathrm{mg} / \mathrm{l}]}\end{array}$ & $\begin{array}{l}\text { Amount found } \\
{[\mathrm{mg} / \mathrm{l}]} \\
\text { mean }\end{array}$ & $\begin{array}{l}\mathrm{SD} \\
{[\mathrm{mg} / \mathrm{l}]}\end{array}$ & $\begin{array}{l}\mathrm{CV} \\
{[\%]}\end{array}$ & $\mathrm{n}$ \\
\hline Carbamazepine epoxide & 0.9909 & $\begin{array}{l}3.0 \\
1.0\end{array}$ & $\begin{array}{l}3.08 \\
1.00\end{array}$ & $\begin{array}{l}0.172 \\
0.089\end{array}$ & $\begin{array}{l}5.6 \\
8.9\end{array}$ & $\begin{array}{l}8 \\
8\end{array}$ \\
\hline Carbamazepine & 0.9919 & $\begin{array}{l}3.0 \\
5.0\end{array}$ & $\begin{array}{l}3.11 \\
5.21\end{array}$ & $\begin{array}{l}0.146 \\
0.090\end{array}$ & $\begin{array}{l}4.7 \\
1.7\end{array}$ & $\begin{array}{l}8 \\
8\end{array}$ \\
\hline Lamotrigine & 0.9913 & $\begin{array}{l}3.5 \\
6.0\end{array}$ & $\begin{array}{l}3.29 \\
6.16\end{array}$ & $\begin{array}{l}0.261 \\
0.486\end{array}$ & $\begin{array}{l}7.9 \\
7.9\end{array}$ & $\begin{array}{l}8 \\
8\end{array}$ \\
\hline
\end{tabular}

\section{Conclusion}

Therapeutic drug monitoring of antiepileptic drugs is mainly achieved by immunoassays because these methods can be mechanized and are computerized. For lamotrigine, however, determination by immunoassay, although described in the literature $(7,8)$, is presently not commercially available. In recent years several HPLC methods for quantitation of lamotrigine have been published (6). The present GC-MS method, however, has not been described before. The GC-MS method presented in this paper seems to be advantageous for measurements of samples from patients on an add-on therapy of lamotrigine with other antiepileptic drugs.
The application of GC-MS is supported by the availability of a simple, effective and reproducible sample preparation procedure. As experienced with various extraction procedures (10), the use of a modified commercial extraction kit (see procedures) gave a clean extract with good recovery and precision. Although this step is not necessary for immunoassay, it opens the possibility to determine coadministered antiepileptic and other drugs from the same extract. Together with the advantages provided by GC-MS, which are achieved by correlation of two properties (retention time and mass spectrum), a high certainty of identification is given. This is especially the case when using 5 fragment masses in the
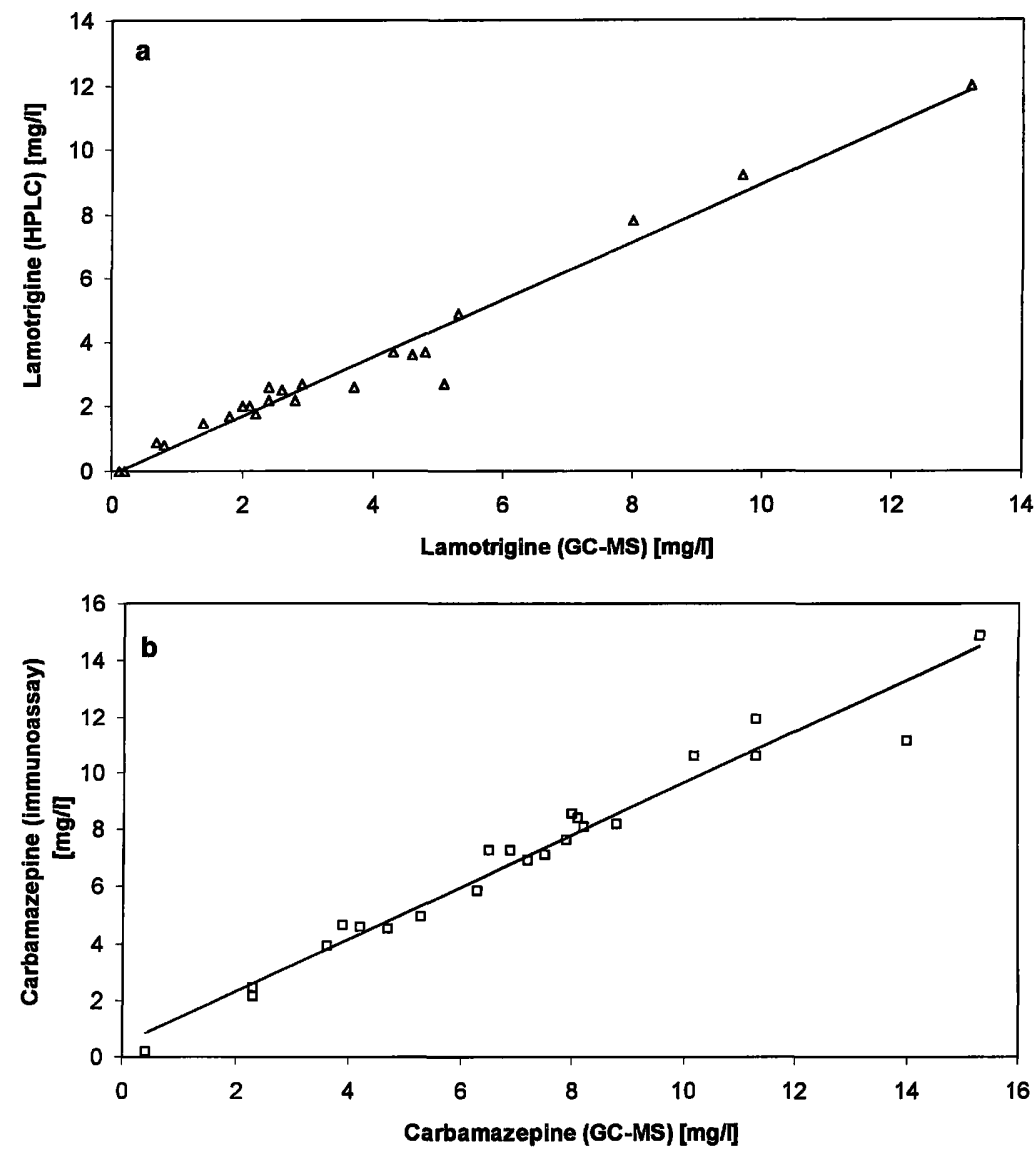

Fig. 4 Comparison of GC-MS and HPLC (immunoassay) results from patient samples. 4a: Lamotrigine $(n=23) ; y=0.905 x-0.091 ; r^{2}=0.964$ 4b: Carbamazepine $(n=23) ; y=0.915 x+0.519 ; r^{2}=0.961$ 
SIM-mode. The self established spectra of 5 masses allow identification of substances with high accuracy. No interference from other drugs present in patient samples was observed. The certainty of identification seems at least to be comparable to HPLC with diode-array-detection. In future the combination of the excellent chromatographical behaviour of antiepileptics with HPLC and the selective identification by MS, i. e. LC-MS may be the most suitable technique possible, probable for TDM in general.

Under practical aspects GC-MS seems today to be superior to HPLC because the detection limit (not only signal to noise ratio) is lower and no change of the column or solvent is necessary, if another group of compounds has to be analysed. Therefore the GC-MS equipment can be

\section{References}

1. Kraemer G, Seddigh S, Bredel-Geißler A. A new antiepileptic drug for add-on therapy of hitherto refractory epilepsies. Akt Neurol 1993; 20:111-22.

2. Ramsay RE, Pellock JM, Garnett WR, Sanchez RM, Valakas AM, Wargin WA, et al. Pharmacokinetics and safety of lamotrigine in patients with epilepsy. Epilepsy Res 1991; 10:191-200.

3. Kraemer G. Relevance of plasma level determinations of antiepileptic drugs. Fortschr Neurol Psychiat 1989; 57:411-24.

4. Wolf P. Lamotrigine: preliminary clinical observations on pharmacokinetics and interactions with traditional antiepileptic drugs. J Epilepsy 1992; 5:73-9.

5. Uges DRA. Referentiewaarden van xenobiotica in humaan materiaal. Pharm Weekblad 1995; 130:180-204.

6. Fazio A, Artesi C, Russo M, Trio R, Oteri G, Pisani F. A liquid chromatogrophic assay using a high-speed column for the determination af lamotrigine, a new antiepileptic drug, in human plasma. Ther Drug Monit 1992; 14:509-12.

7. Biddlecombe RA, Dean KL, Smith CD, Jeal SC. Validation of a radioimmunoassay for the determination of human plasma used in one sequence (without technical changes) for confirmation of screening results in drug abuse testing, for general unknown screening, and e. g. for therapeutic drug monitoring. This variability cannot be achieved with HPLC. Laboratories with low sample input should consider this if they want to establish a chromatographic technique.

\section{Acknowledgements}

We appreciate very much the cooperation of Dr. Holger Lerche from the Institute of Pharmacy and Food Chemistry of LudwigMaximilians-University, Munich, who verified the mass spectrum of lamotrigine. For providing us with extraction vials and standard material we thank Mr. Bauer from Recipe Corporation, Munich (Germany).

concentrations of lamotrigine. J Pharm Biomed Analysis 1990; 8:691-4.

8. Sailstad JM, Findlay JWA. Immunofluorometric assay for lamotrigine in human plasma. Ther Drug Monit 1991; 13:433-42.

9. Pfleger K, Maurer HH, Weber A. Mass spectral and GC data of drugs, poisons, pesticides, pollutants and their metabolites. Weinheim: VCH, 1992.

10. Hallbach J, Vogel H, Michels M, Guder WG. Determination of the antiepileptic drugs in blood by GC-MS and evaluation of different sample extraction procedures. Proc XVI ICCC 285 1996: 114.

\section{Received April 11/ July 24, 1997}

Corresponding author: Dr. Jürgen Hallbach, Institut für Klinische Chemie, Städtisches Krankenhaus Bogenhausen, Englschalkinger Str. 77, D-81925 München, Germany

Tel.: +49 8992702280 , Fax:+4989 92702113 
